\title{
Comparing Occupational Stress Level in Employees of Public and Private Sectors along Age and Gender
}

\author{
Dr. Samita Samaiya ${ }^{1}$
}

\section{ABSTRACT}

In today’s uncertain economy, the best performing employers know that taking their employees' pulse and linking it in to their business goals will help organizations succeed and put them at a competitive advantage. On the other side, due to today's competitive era, role of employees in any organization, are more complex and this complexity may increase their level of stress in their lives, in the organization. The present study was aimed to focus to measure level of occupational stress in employees of two different types of business communities called public and private sector organizations. For the present study, total sample was taken as 240 employees from public and private sector organizations. The age range of employees was 22 years to 41 years. Educational level of employees was minimum graduation. Middle managerial level employees were the sample of the study. Incidental sampling technique was used to collect data through standardized self report inventory, Occupational Stress Index (OSI). The results showed that employees of public and private sectors significantly not found differ in their occupational stress level. Impact of age and gender was also not found on occupational stress.

Keywords: Occupational stress, Public Sector, Private Sector.

The concept of stress was first introduced in the life science by Hans Selye in 1936. It was popularly used in seventeenth century to mean hardship, strain, adversity or affliction. Present day researchers and practitioners visualize the phenomenon of stress in a new perspective. As Kets de Vries (1979) noted, each individual needs a moderate amount of stress to be alert and capable of functioning effectively in an organization (Pestonjee, 1999).

The social-psychologists believe that the intra-psychic needs call into play mechanism of perceptual selection, defense and vigilance. There are wide variations in reaction to stress and the capacity to tolerate it between persons, and in the same individual on different occasions. The most basic fact about stress is that, like feelings, stress is experienced. The feeling of stress is an act in which there is a reference, not a casual relation, to an object that is intended or intentionally presents.

${ }^{1}$ Ph.D, Psychology, Savitribai Phule Pune University

(C) 2015 I S Samaiya; licensee IJIP. This is an Open Access Research distributed under the terms of the Creative Commons Attribution License (http://creativecommons.org/licenses/by/2.0), which permits unrestricted use, distribution, and reproduction in any Medium, provided the original work is properly cited. 
It may prove as an asset as long as it is tolerable and helps in creating healthy competition. Organizational excellence and individual success are achieved through well managed stressors (Pestonjee, 1999). According to Luthans (1995), the phenomenal rate of social and technical change has a great effect on people's lifestyle, and this of course is carried over into their jobs. According to Pareek and Khanna (2011), modern life is full of stress. As organizations become more complex, the potential for and amount of stress increases. Urbanization, industrialization, and the increase in scale of operations are causing increasing stresses. These are the inevitable consequences of socio-economic complexity. People feel stressed as they can no longer have complete control over what happens in their life. There is no escape from stress in modern life. Several terms have been used synonymously with stress. Four terms are similarly used in related literature: stress, strain, conflict, and pressure.

The word 'strain' has been used to denote the effect of stress on the individual. 'Pressure' has been used in the same sense. The word 'conflict' usually denotes incompatibility between two variables: goals, means, ideas etc. The term 'stress' has been used to denote a stimulus (or cause) like an out-of-order telephone; the response (physiological, behavioral, or cognitive changes) to such a cause, for example, heightened blood pressure, quickened breathing, stamping of the foot, perceiving the telephone department as incompetent, etc.; or the resultant state of the organism, for example, indifference, efforts to get the telephone repaired etc. The former has been called eustress and the latter dis-stress. We need 'optimum stress or eustress' to give our best or peak performance. Optimum stress helps us to focus, concentrate, and inspire us towards peak performance.

\section{REVIEW OF LITERATURE}

Many aspects of work environment can be stressful. Some are conditions that occur across most jobs, such as conflicts with co-workers or heavy workloads. Others are specific to particular occupations.

Bano and Jha (2012) conducted study to explore the difference in job related stress between public and private sector employees, based on ten role stressors. They showed in the study that stress level was found moderate in both public and private sector employees and no significant difference was found in overall stress level in public and private sector employees (www.lahoreschoolofeconomics.edu.pk.com). Awan and Jamil (2012) attempted a study to find out differences in overall job stress level of permanent employees in private and public sector banks. Significant difference found in overall job stress level of employees of both public and private sector banks. Employees of private sector bank were found more stressed than employees of public sector banks (www.managementjournals.org). Chaudhary (2012) attempted a study to explore the level of occupational stress among public and private university teachers in Pakistan. The stress level was found moderate in both the groups and there was no significant difference found in stress level of public and private sector university teachers. It was revealed in the study 
that there was no difference in stress level of male and female university teachers (www.pu.edu.pk). Study by Sankpal et al. (2010) focused on the role stress experienced in the banking sector, revealed that there is a significant difference in the role stress between public and private sector bank employees. Private bank employees experienced higher organizational role stress than their public bank counterparts. (www.dhruvacollege.net). Jasmine (1987) conducted a study to compare the level of job related stress among public and private blue collar employees. The analysis of the data revealed that role incumbents of public sector organizations experienced significantly more stress than those of private sector organization. No significant relationship was found between stress and age. Ahmad (2005) found that both the male and female weavers more or less had moderate level of occupational stress. Modekurti and Chattopadhayay (2008) found in their study that levels of stress were more overwhelming in women employees because of greater need to strike a balance between their personal and professional lives (www.dhruvacollege.net).

The various studies related to stress focused on different type of stress in employees, which are related to their work or workplace. From the above review of literature some reasons revealed as important cause of occupational stress these are role of employee in the organization.

Present research was intended to explore the level of occupational stress of employees of two different business communities, public and private sectors. The impact of age and gender on occupational stress were also focused in the present study.

\section{OBJECTIVES OF THE STUDY}

1. To compare whether employees of public and private sector differ in level of occupational stress.

2. To compare whether employees of public and private sector differ in level of occupational stress along age groups.

3. To compare whether employees of public and private sector differ in level of occupational stress along gender.

\section{METHOD}

\section{Hypotheses:}

According to earlier review of literature following hypotheses were framed.

1. There would be significant difference in level of occupational stress in employees of public and private sectors.

2. There would be no significant difference in level of occupational stress in employees along age in public and private sectors.

3. There would be no significant difference in level of occupational stress in employees along gender in public and private sectors.

\section{Sample}

The sampling technique used for the study was incidental sampling. In public sector, various government offices, insurance companies were approached. In private sector, IT companies, 
various production and non-production organizations were approached. The total sample of 240 employees from public and private sector from Pune, Maharashtra, India was selected for the study. The middle managerial level employees were selected for the study. Their minimum educational qualification was graduation. From the total of 240 employees, 120 employees were from public sector and 120 employees from private sector. Out of these 120 employees in each sector, 60 were male and 60 were female employees. Out of these 60 employees of each sector, 30 had age range 22 to 31 years and 30 employees had age range 32 to 41 years.

\section{Tool}

\section{OCCUPATIONAL STRESS INDEX (OSI) SRIVASTAVA AND SINGH, (1981)}

For the measurement of variable stress, the Occupational Stress Index was used. It is a self report inventory. It contains 46 items related to different stressors namely; Role overload, Role ambiguity, Role conflict, Unreasonable group \& political pressure, Responsibility for persons, Under Participation, Powerlessness, Poor peer relations, Intrinsic impoverishment, Low status, Strenuous working conditions, Unprofitability.

\section{Data Collection}

As present research study is based on employees of public and private sector organizations, so initial contact was done in various public and private sector organization like; IT industries, various production and non-production organizations, Insurance companies, and various public sector offices. Their co-operation was solicited and doubts were clarified. The OSI inventory and answer sheets was presented respectively to the participants. Their scores were kept confidential.

\section{Data Analysis}

Means and SDs values were calculated for the raw scores of OSI according to sectors, both the age groups and gender. t- Values were calculated to find out the difference in raw scores of occupational stress in public and private sectors employees. Comparison of scores of occupational stress across the variables, Gender and Age for both public and private sectors was studied by calculating Two-way ANOVA.

\section{RESULTS AND DISCUSSION}

Table 1: Means, SDs, t-value, and 'p' value of OSI of Employees of Public $(\mathrm{N}=120)$ and Private Sectors $(\mathrm{N}=120)$

\begin{tabular}{|l|l|l|l|l|}
\hline Sectors & Means & SDs & 't'- Value & 'p' Value \\
\hline Public & 128.22 & 21.49 & \multirow{2}{*}{$1.69 *$} & 0.05 \\
\hline Private & 124.04 & 16.27 & & \\
\hline
\end{tabular}

$$
{ }^{*} \mathrm{p}<0.05
$$


Figure 1: Graphical Presentation of Occupational Stress of Employees of Public and Private Sectors

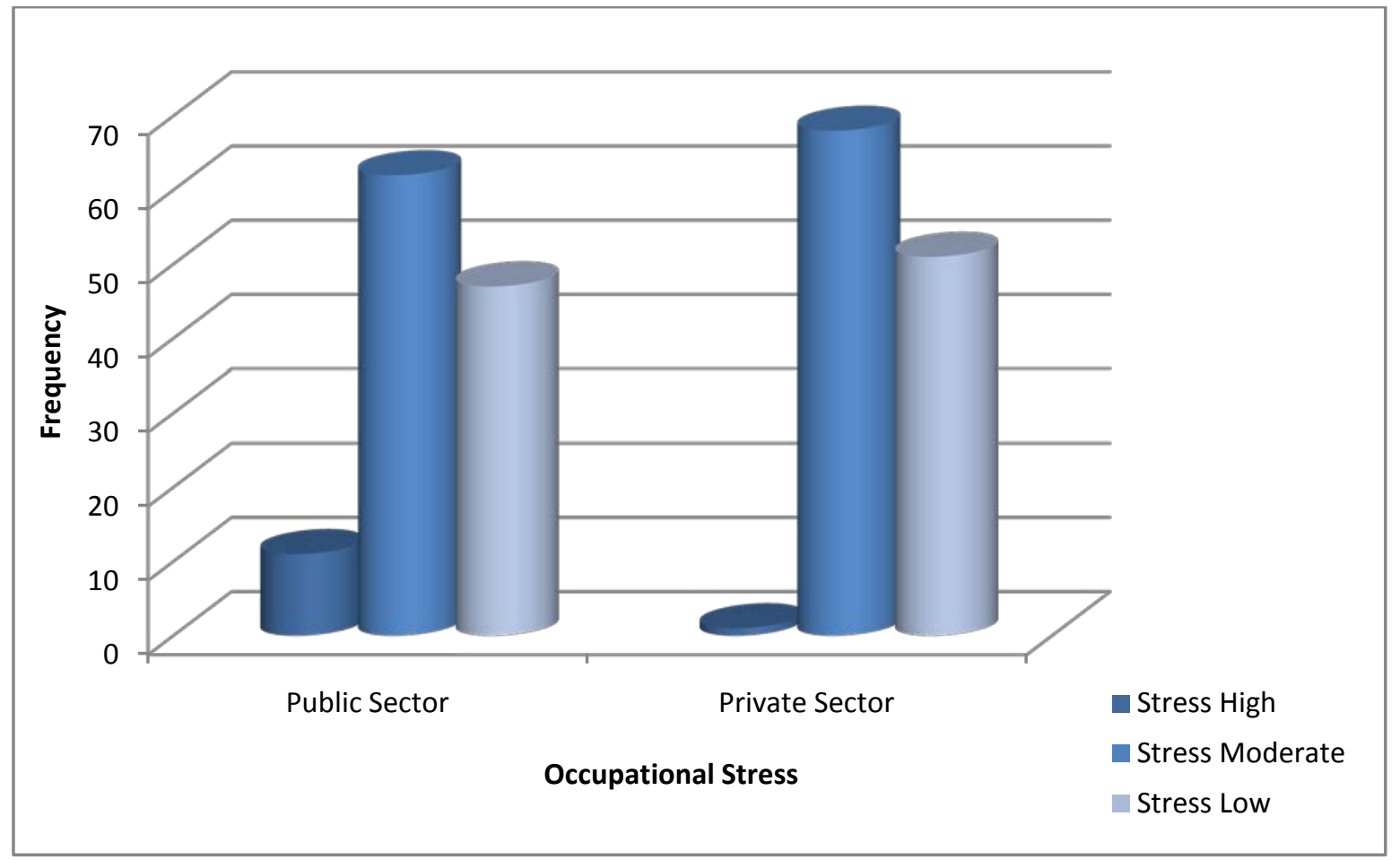

The Figure 1 shows the detailed classification of number of employees of both public and private sectors divided into three levels namely; high, moderate, and low occupational stress. The Figure 1 shows that out of 120 employees of each of the public and private sector, 11 employees $(9.2 \%)$ of public sector and only one employee $(0.8 \%)$ of private sector showed high level of occupational stress. Sixty two employees $(51.7 \%)$ of public sector and 68 employees (56.7\%) of private sector showed moderate level of occupational stress. Forty seven employees (39.2\%) of public sector and 51 employees (42.5\%) of private sector showed low occupational stress level.

\section{$H$ 1: There would be significant difference in level of occupational stress in employees of public and private sectors.}

As shown in the Table 1, mean of the scores of OSI of employees of public sector $(\mathrm{N}=120)$, was 128.22, and SD was 21.49. The mean of the scores on OSI of employees of private sector $(\mathrm{N}=120)$, was 124.04 , and SD was 16.27. ' $\mathrm{t}$ ' value was found $1.69(\mathrm{p}<0.05)$. The result indicates that there is significant difference in stress level of employees of public and private sectors.

Considering the above results, the hypothesis number 1 is retained. 
In Indian corporate culture, the public sector organizations are known for ease and relax working environment from over the years, where job security, clarity about employees' role in the organization, fixed salary, and comparatively less pressure of work may be the reasons for less stress in employees. Whether in private sector organization, in last few years, the practice of human resource development is increased and organizations have started focusing on employees need and expectation, and trying to develop good organizational culture and policies.

Table 2: Means, SDs, F-ratio, and 'p' value of OSI of Employees of Public $(\mathrm{N}=120)$ and Private Sectors ( $\mathrm{N}=120)$ along Age Groups

\begin{tabular}{|l|l|l|l|l|l|l|}
\hline Sectors & Age Group & N & Means & SDs & 'F'-ratio & 'p' Value \\
\hline \multirow{2}{*}{ Public } & A1 & 60 & 130.35 & 20.49 & & \\
\cline { 2 - 5 } & A2 & 60 & 126.10 & 22.42 & \multirow{2}{*}{0.002 NS } & \multirow{2}{*}{0.96} \\
\hline \multirow{2}{*}{ Private } & A1 & 60 & 126.05 & 15.54 & & \\
\cline { 2 - 5 } & A2 & 60 & 122.03 & 16.86 & & \\
\hline
\end{tabular}

A1 (Age 22 to 31 years), A2 (Age 32 to 41 years)

NS=Not Significant

Figure 2: Graphical Presentation of Occupational Stress of Employees of Public and Private Sectors along Age Groups

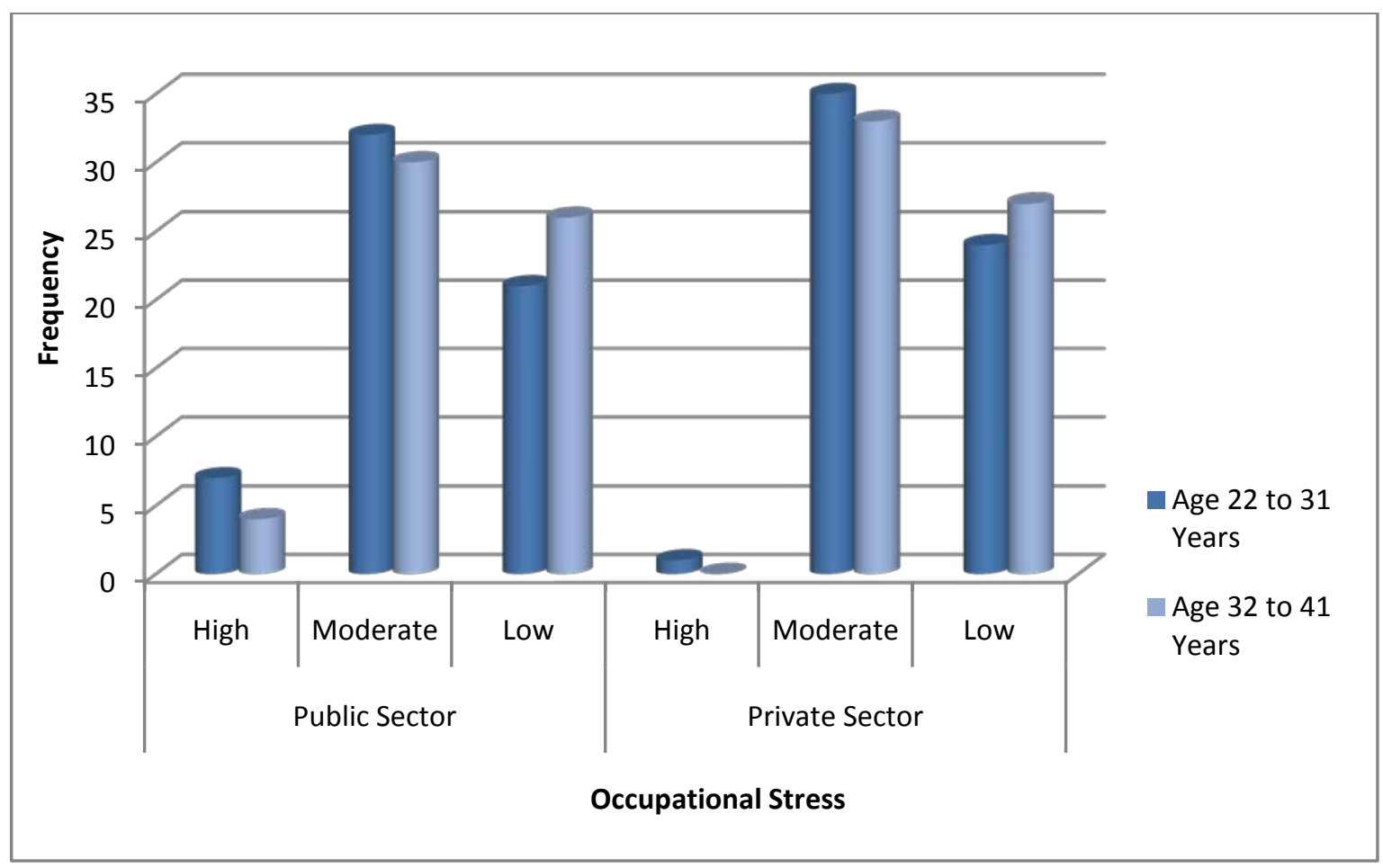


The Figure 2 shows the detailed classification of number of employees of both the age groups A1 (22-31 years), A2 (32-41 years) of public and private sectors divided into three levels - high, moderate, and low occupational stress.

The Figure 2 shows that out of 60 employees of each of the age groups, A1 (22 to 31 Years) and A2 (32 to 41Years) of public sector, seven employees (11.7\%) of A1 and four employees (6.7\%) of A2 indicated high level of stress. Thirty two employees (53.3\%) of A1 and 30 employees (50\%) of A2 indicated moderate stress level. Twenty one employees (35\%) of A1 and 26 employees (43.3\%) of A2 indicated low level of stress related to their occupation.

And out of 60 employees of each of the age groups, A1 (22 to 31 Years) and A2 (32 to 41 Years) of private sector, only one employee (1.7\%) of A1 shown high stress level and no employee of A2 showed high level of stress. Thirty five employees (58.3\%) of A1 and 32 employees (53.3\%) of A2 indicated moderate level of stress. Twenty four employees (40\%) of A1 and 27 employees (45\%) of A2 showed low occupational stress level.

\section{$H$ 2: There would be no significant difference in level of occupational stress in employees along age in public and private sectors.}

As shown in the Table 2, scores of OSI of employees of public sector, age group 1 (22 to 31 Years), mean of the scores was 130.35, and SD was 20.49. Scores of employees of private sector, age group 1, mean of the scores was 126.05, and SD was 15.54. The scores of employees of public sector, age group 2 (32 to 41 Years), mean of the scores was 126.10, and SD was 22.42. The scores of employees of private sector, age group 2, mean of the scores was 122.03, and SD was 16.86. The ' $\mathrm{F}$ ' ratio was found 0.002 ( $\mathrm{p}<0.96 \mathrm{NS}$ ). The results indicate that employees of public and private sector of both age groups have moderate level of stress and there is no significant difference in the level of stress in employees of public and private sectors along their age group.

Considering the above results, the hypothesis number 2 is retained

The most basic fact about stress is that, like other feelings, stress is experienced. It is not earned or learned mechanism which may change very often. Any transition or change produces stress. Mostly employees report constant stress level at early and middle of their age and career. It may change only after the age of 50 to 55 when it is the time of retirement. Present study was focused on age group A1 (22-31 Years) and A2 (32-41 Years) which was the age group of employees who were at starting or middle at their career, this may be the reason that no significant difference found in their stress level in both public and private sectors. 
Table 3: Means, SDs, 'F' ratio, and 'p' value of OSI of Male and Female Employees of Public and Private Sectors

\begin{tabular}{|l|l|l|l|l|l|l|}
\hline Sectors & Genders & N & Means & SDs & 'F' ratio & 'p' Value \\
\hline \multirow{2}{*}{ Public } & Male & 60 & 128.75 & 22.64 & & \\
\cline { 2 - 5 } & Female & 60 & 127.70 & 20.46 & \multirow{3}{*}{0.23 NS } & \multirow{2}{*}{0.63} \\
\hline \multirow{2}{*}{ Private } & Male & 60 & 123.38 & 17.56 & & \\
\cline { 2 - 5 } & Female & 60 & 124.70 & 14.99 & & \\
\hline
\end{tabular}

NS=Not Significant

Figure 3: Graphical Presentation of Occupational Stress of Male and Female Employees of Public and Private Sectors

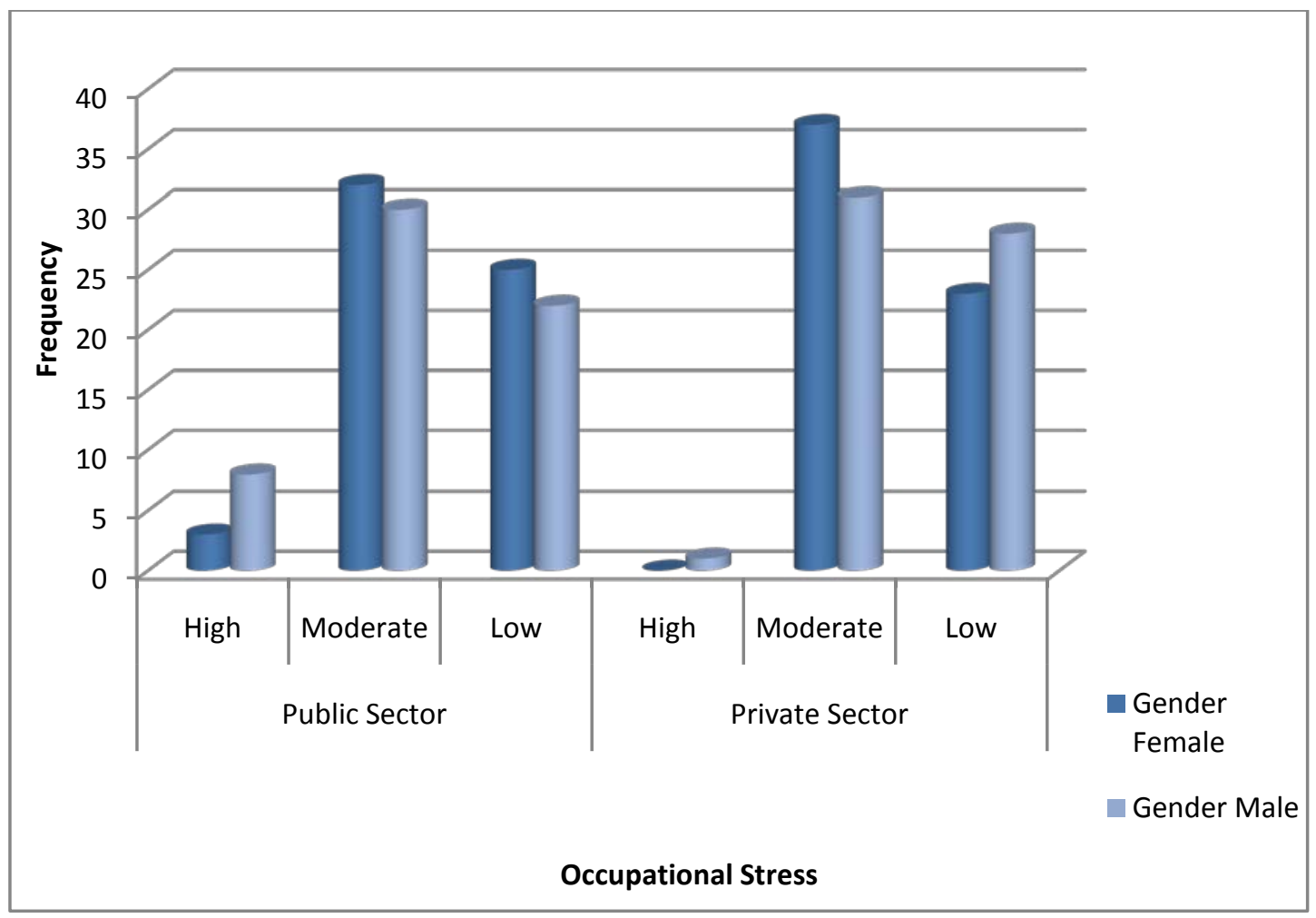

The Figure 3 shows the detailed classification of number of male and female employees of public and private sectors divided into three levels - high, moderate, and low occupational stress.

The Figure 3 shows that out of 60 male employees of each of the sectors, eight employees (13.3\%) of public sector have showed high stress level, while only one employee (1.7\%) of private sector found highly stressed. Thirty employees (50\%) of public sector and 31 employees $(51.7 \%)$ of private sector showed moderate stress. Twenty two employees 
(36.7\%) of public sector and 28 employees (46.7\%) of private sector have shown low stress level.

On the other side, out of 60 female employees of each of the sectors, three employees (5\%) of public sector have shown high stress level, while high stress level was not found in female employee of private sector. Thirty two employees (53.3\%) of public sector and 37 employees $(61.7 \%)$ of private sector have shown moderate stress. Twenty five employees (41.7\%) of public sector and 23 employees (38.3\%) of private sector have shown low stress level.

\section{$H$ 3: There would be no significant difference in level of occupational stress in employees along gender in public and private sectors.}

As shown in the Table 3, scores of OSI of public sector male, mean of the was 128.75, and SD was 22.64, while scores of private sector male, mean of the scores was 123.38, and SD was 17.56. On the other side, scores of public sector female, mean of the scores was 127.70, and SD was 20.46, while scores of private sector female, mean of the scores was 124.70, and SD was 14.99. The ' $\mathrm{F}$ ' ratio was found 0.23 ( $\mathrm{p}<0.63 \mathrm{NS}$ ). The result indicates that both male and female employees experienced moderate level of stress and there is no significant difference in level of stress between male and female employees of public and private sectors.

Considering the above results, the hypothesis number 3 is retained.

In India, in last few decades when women started working outside from home, initially it was difficult them to handle the responsibilities at job as well as at home. At the same time feeling of insecurity at job, unsafe environment, lack of social support were the important reasons of stress in women. Now the situation is totally changed. Now because of changing culture and environment, and supporting attitude of family members, and equal opportunity, and safe working environment lower the stress level of women.

In earlier research it was indicated difference in stress in employees of public and private sectors (Awan \& Jamil, 2012), findings revealed moderate stress in both public and private sectors employees, and there was significant difference in overall level of stress $(\mathrm{t}=1.69$, $\mathrm{p}<0.05$ ) in employees of public and private sectors. The finding supports the previous findings. No relationship between age groups and stress was observed in employees of public and private sectors ( $\mathrm{F}=0.002, \mathrm{p}<0.96 \mathrm{NS}$ ), which is similar to earlier finding which indicated no significant relationship between stress and age (Jasmine, 1987). With respect to gender of employees, earlier significant difference was observed (Ahmad, 2005), just contrast to that, difference in stress level was not found in male and female employees of both public and private sectors $(\mathrm{F}=0.23, \mathrm{p}<0.63 \mathrm{NS})$. This finding supports the some earlier 
research which also indicated no significant difference in stress level of male and female teachers of public and private universities (Chaudhary, 2012).

\section{CONCLUSIONS}

1. There is significant difference in occupational stress in employees of public and private sectors.

2. There is no significant difference in occupational stress employees along age in public and private sectors.

3. There is no significant difference in occupational stress in male and female employees of public and private sectors.

\section{LIMITATIONS OF THE STUDY}

The limitation of the study that it was not based on any one kind of job profile of employees. Employees of various job profile and various departments were included in the study. Work experience in years of employees also was not considered. The present study was based only on one city Pune, Maharashtra, India. Further studies can be undertaken in different cities and other than middle managerial level employees.

\section{REFERENCES}

Ahmad, A. (2005). Perceived occupational stress: A comparative study of men and women weavers of textile industries. Social Science International, 21(1), 29-38.

Awan, Z. K., \& Jamil, F. (2012). A comparative analysis: Difference in overall job stress level of permanent employees in private and public sector banks. International Journal of Economics and Management Sciences, 1(10), 45-58. Retrieved on 5.04.2014 from www.managementjournals.org/ijems.

Bano, B., \& Jha, R. K. (2012). Organizational role stress among public and private sector employees: A comparative study. The Lahore Journal of Business, 1(1), 23-36. Retrieved on 01.10.2013 from www.lahoreschoolofeconomics.edu.pk. com.

Chaudhary, A. Q. (2012). An analysis of relationship between occupational stress and demographics in Universities: The case of Pakistan. Bulletin of Education and Research, 34(2), 1-18. Retrieved on 5.04.2014 from www.pu.edu.pk.

Jasmine, R. (1987). A comparative study of private and public sector blue-collar employees on job related stress. Unpublished M.Phill. Dissertation, Calicut University, Calicut.

Kets de Vries, M. F. R. (1979). Organizational stress: A call for management action. Sloon Management Review, 21(1), 3-14.

Luthans, F. (1995). Organizational behaviour. In Luthans, F. \& Davis, K (Eds.). New York: McGraw-Hill.

Modekurti, M., \&Chattopadhayay, R. (2008). The relationship between organizational role stress and life satisfaction level among women employees: An empirical study. The ICFAIAN 
Journal of Management Research, 7(5), 25-34. Retrieved on 9.12.2013 from www.dhruvacollege.net/.../vidwat\%20(vol\%203\% 201ss\%20).

Pareek, U. (2011). Understanding organizational behaviour. In Pareek, U. \& Khanna, S (3 ${ }^{\text {rd }}$ Eds.). New Delhi: Oxford University Press.

Pestonjee, D. M. (1999). Stress and coping: the Indian experience. New Delhi: Sage Publications.

Sankpal, S., Negi, P., \&Vashishtha, J. (2010). Organizational role stress of employees: Public vs. private banks. The Indian Journal of Management, 3(1), 4-16. Retrieved on 9.12.2013 from www.dhruvacollege.net/..../vidwat\%20(vol\%203\% 201ss\%20).

Selye, H. (1936). Thymus and adrenals in the response of the organism to injuries and intoxifications. British Journal of Experimental Psychology, 17, 114-120.

Srivastava, A. K., \& Singh, A. P. (1981). Manual of Occupational Stress Index. Varanasi: Manovaigyanic Parikshan Sansthan. 